\title{
An investigation of the chest radiographs in a controlled trial of busulphan, cyclophosphamide, and a placebo after resection for carcinoma of the lung
}

\author{
H. STOT T ${ }^{1}, R$. S T E P H E S ${ }^{1}$, WA L L A E F O X ${ }^{1}$, \\ G. S I MO N ${ }^{2}$, a n d D. C. RO Y ${ }^{3}$
}

MRC Tuberculosis and Chest Diseases Unit ${ }^{1}$, Brompton Hospital $^{2}$, Fulham Road, London SW3 6 HP, and Department of Medicine, Banaras Hindu Hospital, Varanasi-221005, India ${ }^{3}$

\begin{abstract}
Stott, H., Stephens, R., Fox, W., Simon, G., and Roy, D. C. (1976). Thorax, 31, 265-270. An investigation of the chest radiographs in a controlled trial of busulphan, cyclophosphamide, and a placebo after resection for carcinoma of the lung. A standard series of radiographs of 588 patients allocated at random to treatment with busulphan (B patients), cyclophosphamide (C patients), or a placebo ( $P$ patients) for two years after surgery for bronchial carcinoma were viewed in three stages (following procedures which avoided bias) by an independent assessor, unaware of the allocated treatment of any patient, with a view to identifying pulmonary changes due to busulphan.

Radiographic appearances consistent with busulphan lung were not reported in any of the $195 \mathrm{~B}$ patients (receiving a mean dosage of $464 \mathrm{mg}$ of busulphan over 301 days) or of the $192 \mathrm{C}$ patients but were present in one of the 201 patients receiving placebo.
\end{abstract}

In 1964 a Medical Research Council Working Party undertook a double-blind cooperative study of long-term cytotoxic chemotherapy after surgery for carcinoma of the bronchus. The results of treatment at random with busulphan, cyclophosphamide, or placebo in over 700 patients have been reported for the first two years after operation (Medical Research Council Working Party, 1971) and a report at five years is in preparation. There have been reports of the occurrence of what is now commonly termed 'busulphan lung', characterized by cough, dyspnoea, fever, and usually bilateral diffuse infiltrations in patients under treatment with busulphan (Oliner et al., 1961; Leake et al., 1963; Heard and Cooke, 1968). The opportunity was therefore taken to investigate radiographic abnormalities occurring in the five-year period in the lungs of patients receiving busulphan in comparison with those receiving cyclophosphamide or placebo.

\section{PLAN AND CONDUCT}

PATIENTS In all, 726 patients with carcinoma of the bronchus drawn from 23 chest centres throughout Britain between January 1965 and January 1968 were admitted to the main study of cytotoxic chemotherapy (Medical Research Council Working Party, 1971). They had had the diagnosis confirmed histologically and had no detectable extrathoracic metastases, and at operation all visible intrathoracic growth had been resected.

CHEMOTHERAPY The procedure for random allocation to a drug regimen and the dosages have already been reported in detail (Medical Research Council Working Party, 1971). In brief, immediately after the successful removal of all visible growth a patient was randomly allocated to receive tablets of busulphan (B series), cyclophosphamide ( $C$ series), or an indistinguishable placebo (P series) by mouth for two years.

For the first 10 days of therapy every patient received eight tablets in a single dose daily, the dosage of active agent in the B series being $4 \mathrm{mg}$ busulphan daily and in the $C$ series $200 \mathrm{mg}$ cyclophosphamide daily.

Maintenance therapy began on the 11th day, and during the first phase of the intake all patients 
were prescribed six tablets in one dose daily, equivalent to $3 \mathrm{mg}$ of busulphan in the B series or $150 \mathrm{mg}$ of cyclophosphamide in the $\mathrm{C}$ series (early intake). However, because of an unexpectedly high incidence of clinical and haematological toxicity the maintenance dosages were reduced, nearly one year after the intake had begun, to busulphan, $1.5 \mathrm{mg}$ daily, and cyclophosphamide, $75 \mathrm{mg}$ daily, all patients (including those receiving placebo) being prescribed three tablets in one dose daily (late intake).

The maintenance dosage was controlled by the physician at monthly intervals on the basis of symptoms and the blood picture, including platelet count. The study was conducted 'double-blind' throughout the two-year period of medication and the subsequent three-year follow-up, neither the patient nor the physician knowing the allocated therapy.

MANAGEMENT OF THE PATIENT Follow-up reports were obtained monthly for the first three years and three-monthly thereafter. A chest radiograph was taken monthly for the first six months and three-monthly thereafter.

Clinical side effects, which were mainly gastric upsets, were managed by giving the medicament in divided doses and, if this was ineffective, by reducing or temporarily interrupting the drug. Only if this failed was the treatment stopped. For haematological abnormalities the medicament was normally interrupted if the platelet count fell below $100 \times 10^{\circ} / 1\left(100000 / \mathrm{mm}^{3}\right)$ or if the total white count fell below $2 \times 10^{\circ} / 1\left(2000 / \mathrm{mm}^{3}\right)$ or slowly below $1 \times 10^{\circ} / 1\left(1000 / \mathrm{mm}^{3}\right)$. If a patient died a necropsy was done when possible.

REGULARITY OF DRUG TAKING Wherever possible a home visit was made without warning during each month in the first two years by a health visitor in order to assess the regularity of self-administration of the patient's medication by a count of the stock of tablets.

\section{RESULTS}

Of $726(243 \mathrm{~B}, 234 \mathrm{C}, 249 \mathrm{P})$ patients admitted to the study, 137 ( $47 \mathrm{~B}, 42 \mathrm{C}, 48 \mathrm{P}$ ) have been excluded from the radiographic assessments, 136 because their radiographs had been lost or destroyed because the patient had died, and one (B) patient because her medication had been stopped after one week due to a psychiatric condition. After these exclusions there remained 588 patients (195 B, 192 C, 201 P) with a series of radiographs available for assessment.
DURATION OF TREATMENT WITH THE ALLOCATED REGIMEN Although the tablets were prescribed for two years, in the event the mean period fos which the 588 patients actually received them wo considerably less, being 301 days for the busubphan, 445 days for the cyclophosphamide, and 527 for the placebo series. Thus, many patien received less than their full course. This was dute principally to the substantial number of deatis which occurred in the first two years in all thre series and to interruptions and/or the prematuro termination of treatment for side effects, which was especially common in the busulphan series. is

RADIOGRAPHIC ASSESSMENTS A standard series of radiographs for each patient was shown to an independent assessor (GS). For patients who were alive at five years he viewed the pretreatment radiograph together with those at $3,6,12,18,24 \frac{1}{3}$ 36,48 , and 60 months, and for patients who had died he viewed the standard series up to the time of death and the two most recent radiographs before death. In addition, for any patient whose medication had been interrupted or stopped o, account of toxicity he viewed the radiograpt nearest to the date of each interruption of termination.

The series of radiographs were viewed by the assessor in three stages (Table). In the first stage he viewed the full series for the 588 patients twice, being unaware of any clinical details of the treatment of any patient or even the dates of which the radiographs were taken. He considere that there were radiographic abnormalities (othey than those normally associated with resection) in 151 patients (61 B, $45 \mathrm{C}, 45 \mathrm{P})$. Reviewing these 151 patients, the cause was clearly evident in 95 84 being extension of growth and/or lung metastases, nine pleural effusions, one pneumothorax and one abnormally large heart shadow.

In the second stage, he reviewed the radios graphic series of the remaining 56 patients, being provided with the dates of the radiographs and the dates during which a medicament was being pre scribed (but not which medicament). From this information he was able to relate the date of the first appearance of the shadows and their progres $\$$ to actual periods when the patients were receiving their allocated medicament. In 22 (14 B, 5 CD $3 \mathrm{P})$ the radiographic shadowing had first appeare $\Phi^{+}$ after the medicament had been stopped (Table) in all at least one month after and in 13 more than two years after. Of these 22, there were four patients (all B) who developed the shadowing within three months of stopping medication; the 
T A B L E

RESULTS OF THE THREE STAGES OF RADIOGRAPHIC VIEWING

\begin{tabular}{|c|c|c|c|c|c|}
\hline \multirow{2}{*}{$\begin{array}{l}\text { Stage of } \\
\text { Viewing }\end{array}$} & \multirow{2}{*}{ Assessment } & \multicolumn{4}{|c|}{ Series } \\
\hline & & All & $\begin{array}{l}\text { Busulphan } \\
\text { (B) }\end{array}$ & $\begin{array}{l}\text { Cyclophosphamide } \\
\text { (C) }\end{array}$ & $\begin{array}{l}\text { Placebo } \\
\text { (P) }\end{array}$ \\
\hline $\begin{array}{ll}\text { First } & \text { I } \\
& \text { II }\end{array}$ & $\begin{array}{l}\text { Patients with radiographs available } \\
\text { Patients with abnormal shadowing } \\
\text { Definite diagnoses of growth, pleural effusion, etc. }\end{array}$ & $\begin{array}{r}588 \\
151 \\
95\end{array}$ & $\begin{array}{r}195 \\
61 \\
34\end{array}$ & $\begin{array}{r}192 \\
45 \\
28\end{array}$ & $\begin{array}{r}201 \\
45 \\
33\end{array}$ \\
\hline Second & $\begin{array}{l}\text { Remaining patients with radiographic abnormalities } \\
\text { Abnormality not attributable to medicament: } \\
\text { (a) first appeared after medicament stopped } \\
\text { (b) disappeared or regressed on medicament }\end{array}$ & $\begin{array}{l}56 \\
22 \\
15\end{array}$ & $\begin{array}{r}27 \\
14 \\
7\end{array}$ & $\begin{array}{l}17 \\
5 \\
6\end{array}$ & $\begin{array}{r}12 \\
3 \\
2\end{array}$ \\
\hline Third & $\begin{array}{l}\text { Remaining patients with radiographic abnormalities } \\
\text { Abnormality diagnosed as: } \\
\text { (a) terminal event } \\
\text { (b) infection, metastases, etc. } \\
\text { (c) consistent with 'busulphan lung' }\end{array}$ & $\begin{array}{r}19 \\
10 \\
8 \\
1\end{array}$ & $\begin{array}{l}6 \\
0 \\
0\end{array}$ & $\begin{array}{l}3 \\
3 \\
0\end{array}$ & $\begin{array}{l}1 \\
5 \\
1\end{array}$ \\
\hline
\end{tabular}

abnormality first appeared in three within six weeks of death. In the fourth, who developed myelomonocytic leukaemia, it first appeared one month after busulphan had been stopped, subsequently occurring sporadically for up to five years. In 15 other patients ( $7 \mathrm{~B}, 6 \mathrm{C}, 2 \mathrm{P}$ ) the shadowing either disappeared or regressed while the patient was still receiving the medicament.

There remained $19(6 \mathrm{~B}, 6 \mathrm{C}, 7 \mathrm{P})$ patients in whom the shadowing persisted unchanged or increased in size while the medication was still being given (Table). The assessor reviewed these in the third stage, being provided with the full clinical details, including dates of intercurrent illnesses, of respiratory infections, of the appearance of clinical metastases, and of death but still not the treatment regimen. In $10(6 \mathrm{~B}, 3 \mathrm{C}, 1 \mathrm{P})$, the shadowing was first observed within 21 days of death and was ascribed to terminal respiratory infections, pulmonary oedema and/or metastases. In eight (3 $\mathrm{C}, 5 \mathrm{P}$ ) more, the shadowing was ascribed to intercurrent respiratory infections (4 patients), to infection from a bronchopleural fistula (2 patients), and to metastases ( 2 patients). In the remaining patient he considered that the shadowing was consistent with busulphan lung. This patient, a man aged 54 on admission, was in fact receiving placebo. It was stopped at eight months because the platelet count dropped to $83 \times 10^{4} / 1$ $\left(83000 / \mathrm{mm}^{3}\right)$. However, as the count was normal the following month the tablets were restarted. Although the counts were normal for the next two months the medicament was stopped because of the appearance of mottled shadowing in both lung fields. A lung biopsy was reported (Dr. K. F. W. Hinson) to contain small granulomatous lesions with histological appearances not typical of those described for busulphan lung. Treatment with corticosteroids was started at the time of the appearance of the radiographic shadowing. Six months later the radiograph was normal and remained so subsequently. Corticosteroids were continued for up to five years, at which time the patient was at work and able to walk more than $91 \mathrm{~m}$ (100 yards) on the flat without dyspnoea.

DURATION AND DOSAGE OF BUSUlPHAN Busulphan was prescribed for a two-year period but, mainly on account of haematological toxicity, $33 \%$ of the 195 patients in the present analysis actually received it for a total of less than 200 days, $39 \%$ for 200 to 399 days, $21 \%$ for 400 to 599 days, and only $7 \%$ for 600 days or more, the mean number of days on which it was received being 301 .

If the duration of treatment is measured from the day on which busulphan was started to the last day it was received (that is, including periods of interruption) $27 \%$ of patients received it over a period of less than 200 days, $35 \%$ over a period of 200 to 399 days, $15 \%$ over a period of 400 to 599 days, and $23 \%$ over a period of 600 days or more, the mean being 375 days.

Fifty-eight per cent of the patients on busulphan received a total dosage of less than $500 \mathrm{mg}, 33 \%$ from 500 to $749 \mathrm{mg}$, and $8 \% 750 \mathrm{mg}$ or more, the mean total dosage being $464 \mathrm{mg}$.

\section{DISCUSSION}

Since the first report on busulphan by Galion (1953) the drug has been widely used in the treatment of chronic myelogenous leukaemia. Among the side effects attributed to it is a condition, first described by Oliner et al. (1961) in two patients, 
characterized by cough, dyspnoea, fever, and abnormal radiographic findings. The radiographic abnormalities, which may not always be present, are diffuse, bilateral, lace-like, mottled or nodular opacities. Heard and Cooke (1968), who first termed the condition busulphan lung, have described the histological appearances as those of a fibrinous intra-alveolar oedema associated with large prominent atypical alveolar epithelial cells.

In the present investigation an assessor interpreted the radiographic series in three stages, the possibility of bias being avoided by the procedures followed for viewing the radiographs. In only a single patient was the radiographic abnormality considered to be consistent with busulphan lung, and that patient was one of the 201 who received the placebo tablets; in none of the 195 patients receiving busulphan were any of the radiographic changes ascribed to the drug, nor in any of the 192 who received cyclophosphamide.

It is difficult to assess the frequency of busulphan lung. The relatively few cases reported in the literature suggest that it is uncommon, but the number of patients at risk among whom the reported cases have arisen is usually not given. Considering studies reporting post-mortem findings, Heard and Cooke (1968) found fibrinous intra-alveolar oedema of the lungs at necropsy in six of 14 patients with chronic myelogenous leukaemia treated with busulphan and in one of seven not treated with the drug. Kirschner and Esterly (1971) reported histological changes at necropsy regarded as typical of busulphan lung in one $(3 \%)$ of 40 patients with chronic myelogenous leukaemia treated with busulphan and in none $(0 \%)$ of 41 not treated with the drug, and Woodliff and Finlay-Jones (1972) in three $(8 \%)$ of 39 patients receiving busulphan for chronic myelogenous leukaemia. Koss, Melamed, and Mayer (1965) reported changes in one $(2 \%)$ of 44 patients receiving busulphan, 25 of whom had chronic myelogenous leukaemia. Thus, in a total of 137 necropsies of patients treated with busulphan, mostly for chronic myelogenous leukaemia, histological appearances attributed to busulphan lung were found in $11(8 \%)$, and in four $(3 \%)$ of these radiographic abnormalities had been reported.

The absence of radiographic abnormalities in the present series might be a consequence of the relatively low total dosage of busulphan. The patients were due to receive busulphan daily for two years but because of a high mortality from carcinoma of the lung during the period and the need to lower the maintenance dose and sometimes interrupt or terminate chemotherapy on account of toxicity, the mean total dosage re ceived was $464 \mathrm{mg}$ over a mean period of just over one year. This is considerably less than th mean total dosage of 3000 to $4000 \mathrm{mg}$ receive over a period of approximately four years by $2 \mathcal{2}$ patients reviewed in the literature with 'typicalos radiographic and histological appearances o $\vec{P}$ busulphan lung (Oliner et al., 1961; Leake et al., 1963; Koss et al., 1965; Harrold, 1966; Smalley anf Wall, 1966; Min and Györkey, 1968; Heard and

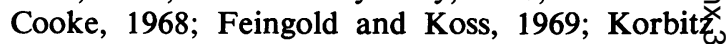
and Reiquam, 1969; Littler et al., 1969; Burns McFarland, and Matthews, 1970; Comhaire et al. 1970; Kolarz, Pietschmann, and Regele, 1970\% Pintos Fuentes and Reissenweber, 1970; Massao chusetts General Hospital Case Records, 1971 Batzenschlager et al., 1972; Jeanmart et al., 1972c Brynes et al., 1973; Etcheberry et al., 1973; Podol and Winkler, 1974). Moreover, none of these 25 patients received less than $600 \mathrm{mg}$ of busulphan whereas only $13(7 \%)$ of the patients in the present series received more than this. However in a Medical Research Council (1968) study of chronic granulocytic leukaemia, there was no evio dence of pulmonary fibrosis in 48 adult patient $\$$ who received a mean dose of $1641 \mathrm{mg}$ of busul 8 phan over a period of two years, 42 of whom hat received more than $600 \mathrm{mg}$ and five more tham $3000 \mathrm{mg}$ (Galton, personal communication). ComÐ haire et al. (1972) found no correlations betweep the total dosage of busulphan (ranging from 212 to $1400 \mathrm{mg}$ ) and the vital capacity in 23 patientso

Littler and Ogilvie (1970) found no association between dosage (ranging from 93 to more thais $6000 \mathrm{mg}$ ) and transfer factor in 23 patients suffer ing from myeloproliferative disease. On the otheo hand, Woodliff and Finlay-Jones (1972) reported that three $(12 \%)$ patients, including two witg radiographic abnormalities, of 26 receiving 'long term' busulphan showed histological features ot busulphan lung in specimens obtained at necropsw or lung biopsy compared with none of 13 who haब received 'short-term' busulphan.

Of the 25 patients with radiographic abnormaliê ties reviewed in the literature and referred tQ above, 24 were being treated for chronic myeloo genous leukaemia. Further, it may be relevan that lung abnormalities also occur in patients wit? leukaemia who have not had busulphan. Thus, Nathan and Sanders (1955) have reported pulo monary infiltrations in myelogenous leukaemiå although less frequently than in lymphatic leu 8 kaemia, and Vieta and Craver (1941) have dese cribed peripheral infiltration of the lungs in the radiographs of $8 \%$ of 52 patients with myeloo 
genous leukaemia. There is also necropsy evidence of pulmonary changes similar to those described as busulphan lung. Kirschner and Esterly (1971) found that, in patients with chronic myelogenous leukaemia, fibrinous oedema and fibrosis of the lungs were as common in those who had not received busulphan as in those who had. Heard and Cooke (1968) described intra-alveolar oedema of the lungs in one of seven patients who had not received busulphan and suggested that leukaemia may have a contributory effect in producing the lung damage. There is, therefore, the possibility that the changes in the lung can be the result of the leukaemic process or the leukaemic process modified by busulphan rather than due to busulphan itself.

In conclusion, this report has produced no evidence that busulphan or cyclophosphamide, in the dosages received by the patients, resulted in radiographic abnormalities of the lung. Further, the published series give no reliable evidence on the incidence of lung changes attributed to busulphan or the influence of dosage or duration of busulphan therapy. The position would be clarified if, when reporting individual cases, authors would also report the total number of patients treated with busulphan and full details of the dosage given.

The physicians, surgeons, and pathologists who collaborated in the main study are listed in the earlier report. Their cooperation is again acknowledged and appreciated. We are particularly grateful for the cooperation of the many physicians and their staff who collected patients' radiographs and forwarded them to us for review in the present study.

\section{REFERENCES}

Batzenschlager, A., Oberling, F., Guerbaoui, M., and Vetter, J. M. (1972). Fibrose pulmonaire mortelle avec lésions cellulaires du poumon et du pancréas, attribuées au busulfan. Archives d'A natomie Pathologique, 20, 291.

Brynes, R. K., Mostafavipour, S. H., Fennessy, J. J., and Variakojis, D. (1973). Diagnosis of busulphan lung by transcatheter biopsy. Chest, 64, 771 .

Burns, W. A., McFarland, W., and Matthews, M. J. (1970). Busulfan-induced pulmonary disease: report of a case and review of the literature. American Review of Respiratory Disease, 101, 408.

Comhaire, F., van Hove, W., van Ganse, W., and van der Straeten, M. (1972). Busulphan and the lungs-Absence of lung function disturbance in patients treated with busulphan. Scandinavian Journal of Respiratory Diseases, 53, 265.

_- van der Straeten, M., van Hove, W., van Ganse, W., and Roels, H. (1970). Longafwijkingen tijdens Busulfan behandeling. Acta Tuberculosa et Pneumologica Belgica, 61, 471.

Etcheberry, R., Becker, P., Delmastro, J., and Donoso, H. (1973). Fibrosis alveolar pulmonar por Myleran (Busulfán). Revista Medica de Chile, $101,42$.

Feingold, M. L. and Koss, L. G. (1969). Effects of long-term administration of Busulfan-report of a patient with generalized nuclear abnormalities, carcinoma of vulva and pulmonary fibrosis. Archives of Internal Medicine, 124, 66.

Galton, D. A. G. (1953). Myleran in chronic myeloid leukaemia-results of treatment. Lancet, 1, 208.

Harrold, B. P. (1966). Syndrome resembling Addison's disease following prolonged treatment with busulphan. British Medical Journal, 1, 463.

Heard, B. E. and Cooke, R. A. (1968). Busulphan lung. Thorax, 23, 187.

Jeanmart, L., Klastersky, J., Verhest, A., Debusscher, L., Potvliege, P., Tagnon, H., and Tombroff, M. (1972). Les pneumopathies diffuses au cours de la chimiotherapie par le busulfan et la bleomycine. Journal Belge de Radiologie, 55, 425.

Kirschner, R. H. and Esterly, J. R. (1971). Pulmonary lesions associated with busulfan therapy of chronic myelogenous leukaemia. Cancer, 27, 1074.

Kolarz, G., Pietschmann, H., and Regele, H. (1970). Lungenveränderungen unter Busulphantherapie bei einem Fall von chronischer Myelose. Zentralblatt für allgemeine Pathologie, 113, 539.

Korbitz, B. C. and Reiquam, C. W. (1969). Busulfan in chronic granulocytic leukemia: a spectrum of clinical considerations. Clinical Medicine, 76, 16.

Koss, L. G., Melamed, M. R., and Mayer, K. (1965). The effect of busulfan on human epithelia. The American Journal of Clinical Pathology, 44, 385.

Leake, E., Smith, W. G., and Woodliff, H. J. (1963). Diffuse interstitial pulmonary fibrosis after busulphan therapy. Lancet, 2, 432.

Littler, W. A., Kay, J. M., Hasleton, P. S., and Heath, D. (1969). Busulphan lung. Thorax, 24, 639.

and Ogilvie, C. (1970). Lung function in patients receiving busulphan. British Medical Journal, 4, 530 .

Massachusetts General Hospital Case Records (1971). Case 40-1971. New England Journal of Medicine, 285, 847.

Medical Research Council Working Party (1971). Study of cytotoxic chemotherapy as an adjuvant to surgery in carcinoma of the bronchus: report. British Medical Journal, 2, 421.

Medical Research Council Working Party for Therapeutic Trials in Leukaemia (1968). Chronic granulocytic leukaemia: comparison of radiotherapy and busulphan therapy: report. British Medical Journal, 1, 201. 
Min, K. W. and Györkey, F. (1968). Interstitial pulmonary fibrosis, atypical epithelial changes and bronchiolar cell carcinoma following busulfan therapy. Cancer, 22, 1027.

Nathan, D. J. and Sanders, M. (1955). Manifestations of acute leukemia in the parenchyma of the lung. New England Journal of Medicine, 252, 797.

Oliner, H., Schwartz, R., Rubio, F., Jr., and Dameshek, W. (1961). Interstitial pulmonary fibrosis following busulfan therapy. American Journal of Medicine, 31, 134.

Pintos Fuentes, R. J. and Reissenweber, N. (1970). El pulmon de busulfan. Hoja Tisiológica, 27, 84.

Podoll, L. N. and Winkler, S. S. (1974). Busulfan lung: report of two cases and review of the literature. American Journal of Roentgenology, Radium Therapy and Nuclear Medicine, 120, 151.
Smalley, R. V. and Wall, R. L. (1966). Two cases of busulfan toxicity. Annals of Internal Medicine, 64, 154.

Vieta, J. O. and Craver, L. F. (1941). Intrathoracic manifestations of the lymphomatoid diseases. $\mathbb{\otimes}$ Radiology, 37, 138.

Woodliff, H. J. and Finlay-Jones, L. R. (1972). Busulphan lung. Medical Journal of Australia? 2, 719 .

Requests for reprints to: Dr. H. Stott, MRC Tuber culosis and Chest Diseases Unit, Brompton Hospital, Fulham Road, London SW3 6HP. 